\title{
Aldosterone-producing microadenoma in a patient with primary aldosteronism
}

\author{
H. KANESHIGE \\ M.D. \\ Y. Nомото \\ M.D.
}

\author{
M. ENDOH \\ M.D. \\ H. SAKAI \\ M.D.
}

\begin{abstract}
S. ARIMORI M.D.

Department of Internal Medicine, School of Medicine Tokai University, Isehara City, Kanagawa-ken, 259-11, Japan
\end{abstract}

\begin{abstract}
Summary
A 54-year-old patient was found to have an aldosterone-producing microadenoma measuring $2.5 \mathrm{~mm}$ in diameter. Although adrenal venography by selective catheterization had failed to demonstrate the tumour, adrenal scintiscan using ${ }^{131}$ I-19-iodocholesterol accurately localized the functional tumour in the right adrenal gland; a dexamethasone-modified adrenal scintiscan revealed complete suppression of radioactivity in the right adrenal gland. These findings suggest that adrenal scintiscan, together with adrenal vein blood analysis, is capable of detecting a small adenoma before surgery, and that dexamethasone suppression of an adrenal scintiscan does not exclude an adenoma.

\section{Introduction}

Primary aldosteronism is induced by aldosteroneproducing tumours (Conn, 1955) which are often small and difficult to localize. The authors recently encountered a case with an aldosterone-producing microadenoma measuring $2.5 \mathrm{~mm}$ in diameter which could be detected before the surgical operation.
\end{abstract}

\section{Case history}

A 54-year-old male bank employee was admitted to hospital in 1977 because of muscle weakness in the lower extremities with a 2-year history of hypertension, polydipsia and nocturnal polyuria. He had been on hydrochlorthiazide for 3 months before admission. Two weeks before admission, he noticed muscle weakness in the lower extremities which was diagnosed as hypokalaemic myopathy in another hospital and he was referred to the authors' clinic. There was no relevant past history or family history.

Clinical and laboratory findings included: BP $144 / 88 \mathrm{mmHg}$ and grade I hypertensive changes in the ocular fundus. Complete blood count, ESR and urinalysis were normal. The fasting blood glucose concentration was $6.3 \mathrm{mmol} / \mathrm{l}$, blood urea nitrogen $3.2 \mathrm{mmol} / 1$ (normal range $1 \cdot 3-3 \cdot 2$ ), creatinine phosphokinase 4340 u./l (normal range 30-174), serum aldolase $30 \cdot 4 \mathrm{u}$. (normal range $0 \cdot 5-3 \cdot 1$ ), and SGOT $226 \mathrm{u}$./1 (normal range 10-40). Serum electrolytes revealed sodium $145 \mathrm{mmol} / \mathrm{l}$ (normal range 136144), potassium $1.4 \mathrm{mmol} / \mathrm{l}$ (normal range $3.4-4.8$ ) and chloride $86 \mathrm{mmol} / \mathrm{l}$ (normal range 99-109). Blood gas analysis showed pH 7.512, $\mathrm{PCO}_{2} 50 \cdot 5$ $\mathrm{mmHg}, P_{\mathrm{O}_{2}} 60.7 \mathrm{mmHg}$ and base excess, $+14 \cdot 7$. Plasma renin activity was suppressed at $0 \cdot 1 \mu \mathrm{g} / \mathrm{l} / \mathrm{hr}$ even on a low salt diet after $4 \mathrm{hr}$ of standing with administration of frusemide. Serum aldosterone was $4 \mathrm{ng} / \mathrm{dl}$ in the recumbent position. Urinary catecholamine and vanillyl mandelic acid were in the normal ranges. Total urinary 17 -hydroxycorticoids was $24.6 \mu \mathrm{mol} / 24 \mathrm{hr}$ (normal range 12.5-31.6).

Chest X-ray and brain scintiscan were normal. ECG revealed U-waves. In the muscle biopsy of quadriceps femoris, occasional vacuolation and atrophic muscle fibres were seen. Treatment with oral potassium chloride increased the serum potassium value up to $3.5 \mathrm{mmol} / \mathrm{l}$ after 8 days. Adrenal scanning using ${ }^{131} \mathrm{I}-19$-iodocholesterol indicated a functional tumour in the right adrenal gland (Fig. 1) whereas an adrenal scan after $2 \mathrm{mg}$ dexamethasone orally for 6 days demonstrated complete suppression of uptake. Although selective adrenal venography showed negative radiological findings, localization of a right adenoma was confirmed by quantitation of aldosterone in adrenal venous blood samples obtained by selective catheterization. The serum aldosterone level was $>1.6 \mathrm{ng} / \mathrm{dl}$ in the right adrenal vein and $0.16 \mathrm{ng} / \mathrm{dl}$ on the left side.

On the basis of these findings, a diagnosis of 


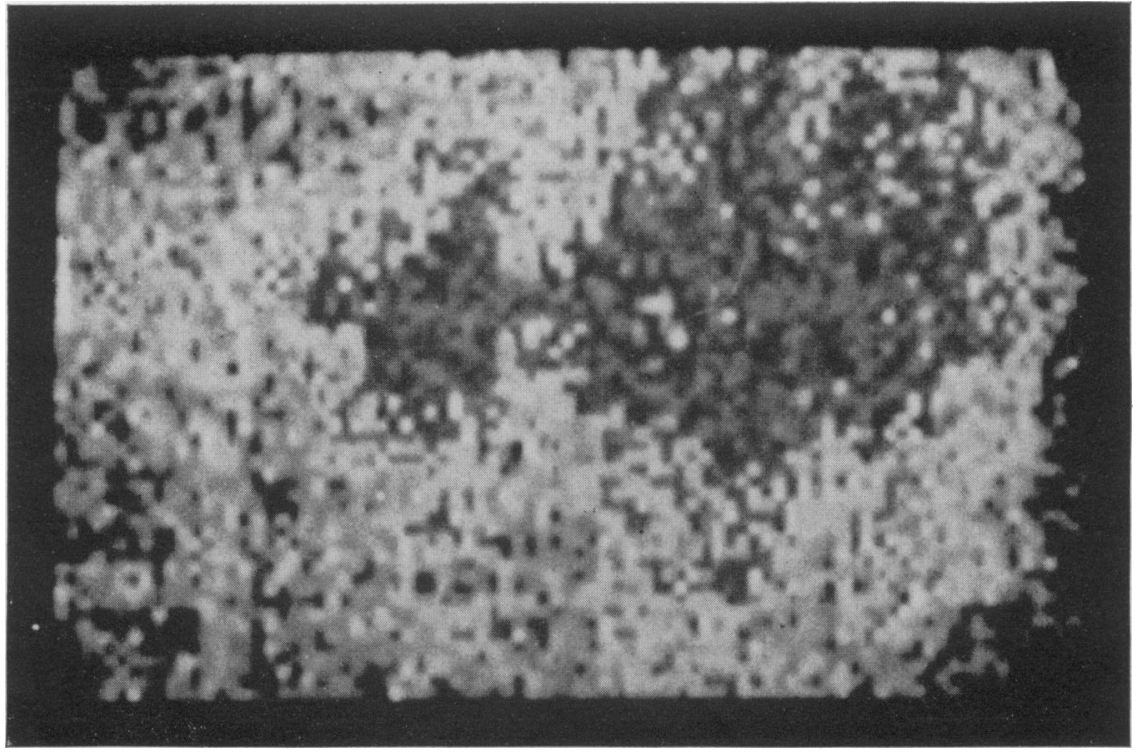

FIG. 1. Posterior image of the adrenal scan 7 days after administration of ${ }^{131}$ I-19-iodocholesterol showing increased activity in the right adrenal gland.

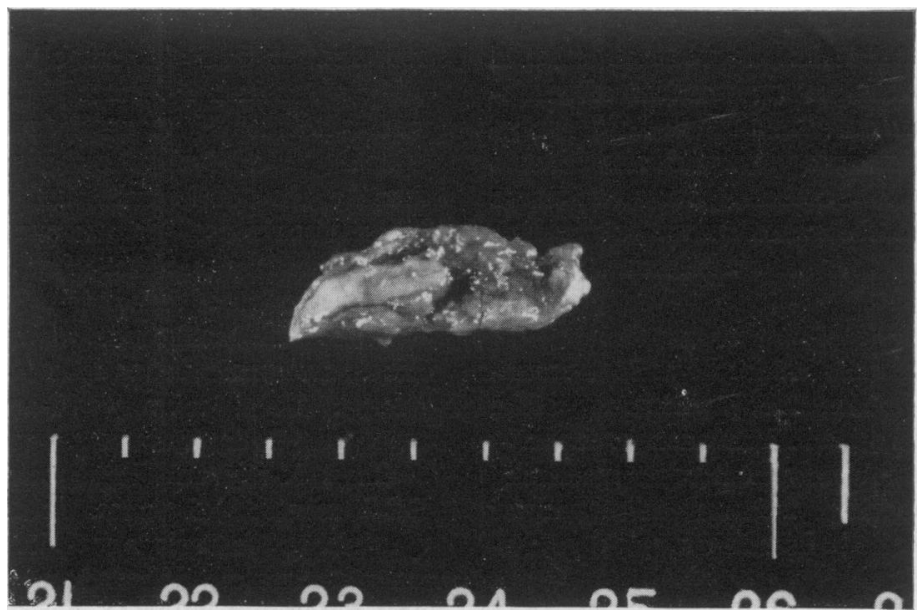

FIG. 2. Aldosterone-producing microadenoma measuring $2.5 \mathrm{~mm}$ in diameter.

primary aldosteronism was made. At operation, a right, golden-yellow microadenoma measuring $2 \cdot 5$ $\mathrm{mm}$ in diameter was obtained (Fig. 2) following which there was a remarkable improvement in the hypokalaemia. Microscopically, the tumour tissue showed the typical appearance of clear and spongicytic cells. To determine aldosterone concentration in the tumour tissue, adenoma tissue was homogenized in $33 \%$ ethanol and the homogenate was diluted with dichlormethane. The amount of aldosterone was quantitated by radioimmunoassay. The result showed that $149.6 \mathrm{ng} / \mathrm{g}$ of aldosterone was presenio in the adenoma tissue homogenate and $0.96 \mathrm{ng} / \mathrm{g}$ ing the non-adenoma specimen.

\section{Discussion}

Primary aldosteronism is an important cause of juvenile hypertension in that it can be cured b. surgical excision (Conn, 1955). In most cases, th $\mathbb{8}$ cause is a unilateral adenoma, and less commo 
bilateral hyperplasia which is not so satisfactorily treated with surgery. Pre-operative distinction between adenoma and hyperplasia is sometimes difficult since a very small adenoma might be overlooked. Although clinical features of the case in this report were compatible with those of primary aldosteronism (Weinberger et al., 1979; Melby et al., 1967), adrenal venography by selective catheterization (Conn et al., 1969) failed to demonstrate the tumour, probably because of its small size. On the other hand, adrenal scintiscan using ${ }^{131}$ I-19-iodocholesterol clearly localized the functional tumour in the right adrenal gland. A dexamethasonemodified adrenal scintiscan was performed to distinguish between adenoma and hyperplasia. This study revealed almost complete suppression of radioactivity in the right adrenal gland, suggesting bilateral hyperplasia (Conn, Cohen and Herwig, 1976). However, an adrenal scintigram and adrenal blood sampling gave the accurate localization of the right $2 \cdot 5-\mathrm{mm}$ diameter micro-adenoma.

It is postulated that the uptake of iodocholesterol into a micro-adenoma can be suppressed by dexamethasone contrary to accepted belief. Further studies are warranted to confirm whether such suppression is an ubiquitous phenomenon in microadenomas of less than $3 \mathrm{~mm}$ in diameter.

In a report of 37 cases of primary hyperaldosteronism, Yune et al. (1976) suggested that adrenal venous blood analysis, adrenal venography and radioisotope scan are 3 important diagnostic tools in the clinical investigation of primary hyperaldosteronism. In addition to these diagnostic procedures, Luetscher et al. (1974) advocate the use of changes in plasma aldosterone measurements with postural responses to differentiate between adrenal adenoma and hyperplasia. Since these observations were mostly based on patients with adenomas of ordinary sizes, it would be of interest to evaluate which diagnostic procedures are capable of detecting microadenomas.

The results observed in this study indicate that a combination of adrenal scintiscan and measurement of aldosterone levels in adrenal venous blood is useful in detecting a microadenoma of $2.5 \mathrm{~mm}$ in diameter, and that the dexamethasone suppression of iodocholesterol uptake does not exclude an adenoma.

\section{References}

CoNN, J.W. (1955) A new clinical syndrome. Journal of Laboratory and Clinical Medicine, 45, 6.

ConN, J.W., Cohen, E.L. \& Herwig, K.R. (1976) The dexamethasone-modified adrenal scintiscan in hyporeninemic aldosteronism (tumor versus hyperplasia). A comparison with adrenal venography and adrenal venous aldosterone. Journal of Laboratory and Clinical Medicine, 88, 841.

Conn, J.W., Rovner, D.R., Cohen, E.L., Bookstein, J.J., Cerny, J.C. \& LuCas, C.P. (1969) Preoperative diagnosis of primary aldosteronism. Archives of Internal Medicine, $123,113$.

Luetscher, J.A., Ganguly, A., Melada, G.A. \& Dowdy, A.J. (1974) Preoperative differentiation of adrenal adenoma from idiopathic adrenal hyperplasia in primary aldosteronism. Circulation Research, 34 (Suppl. 1), 175.

Melby, J.C., Spark, R.F., Dale, S.L., Egdahl, R.H. \& KAHN, P.C. (1967) Diagnosis and localization of aldosterone-producing adenomas by adrenal vein catheterization. New England Journal of Medicine, 277, 1050.

Weinberger, M.H., Grim, C.E., Hollifield, J.W., Kem, D.C., Ganguly, A., Kramer, N.J., Yune, H.Y., Wellman, H.N. \& Donohue, J.P. (1979) Primary aldosteronism. Annals of Internal Medicine, 123, 113.

Yune, H.Y., Klatte, E.C., Grim, C.E., Weinberger, M.H., Donohue, J.P., Yum, M.N. \& Wellman, H.N. (1976) Radiology in primary hyperaldosteronism. American Journal of Roentogenology, 127. 761. 